\title{
Hemodynamic effect of full flexion of the hips and knees in the supine position: a comparison with straight leg raising
}

\author{
Tae Dong Kweon ${ }^{1}$, Chul-Woo Jung ${ }^{2}$, Jin-Woo Park², Yun-Seok Jeon², and Jae-Hyon Bahk² \\ Department of Anesthesiology and Pain Medicine, ${ }^{1}$ Yonsei University College of Medicine, ${ }^{2}$ Seoul National University Hospital, Seoul, \\ Korea
}

Background: Straight raising of the legs in the supine position or Trendelenburg positioning has been used to treat hypotension or shock, but the advantages of these positions are not clear and under debate. We performed a crossover study to evaluate the circulatory effect of full flexion of the hips and knees in the supine position (exaggerated lithotomy), and compare it with straight leg raising.

Methods: This study was a prospective randomized crossover study from the tertiary care unit at our university hospital. Twenty-two patients scheduled for off-pump coronary artery bypass surgery were enrolled. Induction and maintenance of anesthesia were standardized. Exaggerated lithotomy position or straight leg raising were randomly selected in the supine position. Hemodynamic variables were measured in the following sequence: $10 \mathrm{~min}$ after induction, 1, 5, and $10 \mathrm{~min}$ following the designated position, and 1 and $5 \mathrm{~min}$ after returning to the supine position. Ten min later, the other position was applied to measure the same hemodynamic variables.

Results: During the exaggerated lithotomy position, cerebral and coronary perfusion pressure increased significantly $(\mathrm{P}<0.01)$ without a change in cardiac output. During straight leg raising, cardiac output increased at 5 min $(\mathrm{P}<$ 0.05 ) and cerebral and coronary perfusion pressures did not increase except for cerebral perfusion pressure at 1 min. However, the difference between the two groups at each time point in terms of cerebral perfusion pressure was clinically insignificant.

Conclusions: Full flexion of the hips and knees in the supine position did not increase cardiac output but may be more beneficial than straight leg raising in terms of coronary perfusion pressure. (Korean J Anesthesiol 2012; 62: 317-321)

Key Words: Hemodynamics, Positioning.

Received: June 21, 2011. Revised: July 20, 2011. Accepted: July 26, 2011.

Corresponding author: Jae-Hyon Bahk, M.D., Department of Anesthesiology and Pain Medicine, Seoul National University Hospital, 101, Daehak-ro, Jongno-gu, Seoul 110-744, Korea. Tel: 82-2-2072-2818, Fax: 82-2-747-5639, E-mail: bahkjh@snu.ac.kr

(c) This is an open-access article distributed under the terms of the Creative Commons Attribution Non-Commercial License (http:// creativecommons.org/licenses/by-nc/3.0/), which permits unrestricted non-commercial use, distribution, and reproduction in any medium, provided the original work is properly cited. 


\section{Introduction}

Trendelenburg positioning or straight leg raising are commonly used for the treatment of acute hypotension. The Trendelenburg position may cause respiratory difficulty, increased intracranial pressure, increased intraocular pressure, and passive regurgitation of gastric contents [1-3]. Previous studies of the Trendelenburg position did not show any significant clinical benefits [4-6]. Instead, straight leg raising has been advocated to avoid the complications induced by the Trendelenburg position. Straight leg raising is known to increase stroke volume and cardiac output by promoting venous return $[7,8]$. However, the effects were transient with minimal clinical side effects $[6,9]$.

The squatting position is recommended for overcoming the cyanotic spell by means of increasing afterload in patients with cyanotic heart disease. Thereupon, we postulated that full flexion of the hips and knees in the supine position (exaggerated lithotomy position) may be more useful than straight leg raising in addition to absence of the above-mentioned problems of the head-down position. Namely, we hypothesized that the exaggerated lithotomy position increases afterload without serious impediment on venous return, which may improve cerebral or coronary perfusion.

This crossover study was performed to evaluate the hemodynamic effect of the exaggerated lithotomy position and compare it with straight leg raising in the supine position in patients scheduled for coronary artery bypass surgery.

\section{Meterials and Methods}

After obtaining Institutional Review Board approval and informed consent, 22 patients scheduled for elective off-pump 2 or 3 coronary artery bypass surgery were enrolled in the study. Patients with arrhythmia, mitral regurgitation greater than grade 2 , and ejection fraction less than $40 \%$ were excluded.

Patients were premedicated with midazolam IV (0.04 mg/ $\mathrm{kg}$ ) upon arrival at the operating room. After application of routine monitors such as ECG, $\mathrm{SpO}_{2}$ and noninvasive blood pressure (BP) monitoring, the left radial artery was cannulated after local infiltration with $2 \%$ lidocaine. Etomidate $(0.3 \mathrm{mg} /$ $\mathrm{kg})$, midazolam $(0.2 \mathrm{mg} / \mathrm{kg})$ and vecuronium $(0.15 \mathrm{mg} / \mathrm{kg})$ were injected IV for anesthesia induction along with a loading dose of sufentanil ( $1 \mathrm{mcg} / \mathrm{kg})$. Sevoflurane $(1-2 \mathrm{vol} \%)$ and a maintenance dose of sufentanil ( $1 \mathrm{mcg} / \mathrm{kg} / \mathrm{hr}$ ) were used for maintenance and intravenous fluid was infused at a rate of $2-3$ $\mathrm{ml} / \mathrm{kg} / \mathrm{hr}$ during the study.

Tidal volume was set at $10 \mathrm{ml} / \mathrm{kg}$ and respiratory rate was adjusted to maintain $\mathrm{PaCO}_{2}$ between 35-40 mmHg. A pulmonary artery catheter (Swan-Ganz CCOmbo/SvO
Model 744HF75, Baxter Healthcare, Irvine, CA, USA) was inserted via the right internal jugular vein and connected to a monitor (Edwards Vigilance monitor, Edwards Lifescience, Irvine, CA, USA). Transesophageal echocardiography probe (Acuson Sequoia ${ }^{\mathrm{TM}}$ Echocardiography System, Siemens Medical Solutions, Mountain View, CA, USA) was inserted and positioned to observe short axis view of the left ventricle at a midpapillary level.

The study commenced 15 min after endotracheal intubation and no surgical stimulation took place during the study period. After baseline measurements (Ts) were taken in the supine position, straight leg raising (both heels raised about $50 \mathrm{~cm}$ vertically from the surface of the operating table with the knees extended) or the exaggerated lithotomy position were randomly selected on the horizontal operating table. Hemodynamic parameters, including cardiac output (CO), heart rate (HR), mean BP, pulmonary artery wedge pressure (PAWP), central venous pressure (CVP), and left ventricular end-diastolic area (LVEDA) were checked in the following sequence: $1 \mathrm{~min}$ (T1), $5 \mathrm{~min}$ (T5), and $10 \mathrm{~min}$ (T10) after the first designated position and $1 \mathrm{~min}$ (Ts1) and $5 \mathrm{~min}$ (Ts5) after returning to the supine position. Ten min after returning to the supine position, the other position was applied to measure the same hemodynamic variables in the same sequence.

LVEDA, which was defined as the largest left ventricular cross-sectional area after the electrocardiographic T-wave among 4 consecutive cardiac cycles, was measured by manual planimetry of the area circumscribed by the leading edge of the endocardial border. All echocardiographic measurements were recorded by an investigator, and the recorded data manipulations were performed by another investigator blinded to the study protocol. Cardiac index (CI) and left ventricular end-diastolic area index (LVEDAI) were calculated respectively as CO and LVEDA were divided by body surface area [10]. Cerebral perfusion pressure was estimated as mean BP-CVP and coronary perfusion pressure as diastolic BP-PAWP. Systemic vascular resistance was calculated as (mean BP-CVP)/CO] $\cdot 80$ dynes.sec/ $\mathrm{cm}^{5}$.

\section{Statistics}

Statistical analysis was performed using SPSS v12 for Windows (SPSS Inc, Chicago, IL, USA). All data were expressed as mean \pm SD or number of patients (percentage). Sample size calculations were performed based on our preliminary study to compare the hemodynamics between the 2 positions and the following assumptions: significance $(\alpha)$ at 0.05 with paired t test, power $(\beta)$ at 0.8 , and difference of mean value $=6.6 \mathrm{mmHg}$ with $\mathrm{SD}=10.6 \mathrm{mmHg}$ of mean BP. This generated an estimate of 22 patients per group. 
Hemodynamic parameters, such as CI, mean BP, and CVP between 2 positions were compared by 2 -way analysis of variance with replication. Dunnett's test was used for comparisons between Ts value and the other values at each time within each group. Paired t test with Bonferroni correction was used to compare the hemodynamics between the 2 positions at each time.

\section{Results}

Fifteen men and 7 women, who had 2 or 3 coronary artery disease, were recruited for this study (Table 1). ECG showed normal findings except for 3 patients with left ventricular hypertrophy and for a patient with right bundle branch block.

Table 1. Characteristics of Patients Enrolled in this Study

\begin{tabular}{lc}
\hline \multicolumn{1}{c}{ Parameters } & Value \\
\hline Sex (M/F) & $15 / 7$ \\
Age (yr) & $65.0 \pm 8.8$ \\
Height (cm) & $162.0 \pm 8.5$ \\
Weight (kg) & $62.1 \pm 7.0$ \\
Diabetes/Hypertension (n) & $8 / 15$ \\
Diastolic dysfunction (n) & 12 \\
Ejection fraction (\%) & $58.6 \pm 6.5$ \\
Concurrent medication (n) & \\
Beta blocker & 14 \\
Calcium channgel blocker & 6 \\
Nitroglycerine & 19 \\
Angiotensin converting enzyme inhibitor & 3 \\
Angiotensin receptor inhibitor & 4 \\
Diuretics & 4 \\
\hline
\end{tabular}

Data are expressed as mean \pm SD or number of patients.
Twelve patients revealed diastolic dysfunction on preoperative echocardiographic evaluation.

$\mathrm{CI}$ increased significantly only at $5 \mathrm{~min}$ after straight leg raising $(\mathrm{P}<0.05)$, but did not increase in the exaggerated lithotomy position. Mean BP increased only at 1 min after straight leg raising, but increased throughout the exaggerated lithotomy positioning. Pulmonary artery pressure, CVP and PAWP increased at all measurement points in both positions. HR did not change during the study period in both positions (Table 2). LVEDAI increased in both positions $(\mathrm{P}<0.01$, Table 2$)$. SVR increased only at $1 \mathrm{~min}$ after straight leg raising, but increased throughout the exaggerated lithotomy positioning ( $\mathrm{P}<0.01$, Table 2$)$. The estimated cerebral and coronary perfusion pressure increased significantly during the exaggerated lithotomy position $(\mathrm{P}<$ 0.01, Fig. 1). However, the estimated cerebral perfusion pressure increased only at $1 \mathrm{~min}$ after straight leg raising $(\mathrm{P}<0.01)$ and the estimated coronary perfusion pressure did not increase while straight leg raising was applied.

\section{Discussion}

CO increased by straight raising of the legs rather than by fully flexing the hips and knees in the supine position. However, full flexion of the hips and knees seemed to be more beneficial than straight leg raising in terms of coronary perfusion pressure.

Straight leg raising has been reported to increase CI in some previous reports $[8,11]$, but not in others $[6,9]$. This discrepancy may be explained by differences in monitoring techniques, volume status or cardiac function. Kyriakides et al. [11] and colleagues observed cardiac performance with Doppler echo-

Table 2. Comparison of Hemodynamics between SLR and EL

\begin{tabular}{|c|c|c|c|c|c|c|c|}
\hline & Position & Ts & $\mathrm{T} 1$ & T5 & $\mathrm{T} 10$ & Ts1 & Ts5 \\
\hline \multirow{2}{*}{$\begin{array}{l}\text { Cardiac index } \\
\left(\mathrm{L} \cdot \mathrm{min}^{-1} \cdot \mathrm{m}^{-2}\right)\end{array}$} & SLR & $2.3 \pm 0.6$ & $2.4 \pm 0.7$ & $2.5 \pm 0.7^{\dagger}$ & $2.4 \pm 0.7$ & $2.3 \pm 0.5$ & $2.3 \pm 0.6$ \\
\hline & EL & $2.4 \pm 0.6$ & $2.5 \pm 0.7$ & $2.4 \pm 0.5$ & $2.4 \pm 0.5$ & $2.4 \pm 0.6$ & $2.5 \pm 0.6$ \\
\hline \multirow{2}{*}{$\begin{array}{l}\text { Mean blood pressure* } \\
(\mathrm{mmHg})\end{array}$} & SLR & $64 \pm 10$ & $70 \pm 11^{\dagger}$ & $68 \pm 12$ & $65 \pm 11$ & $62 \pm 10$ & $61 \pm 8$ \\
\hline & EL & $62 \pm 9$ & $75 \pm 11^{\dagger, \neq}$ & $70 \pm 11^{\dagger}$ & $67 \pm 10^{\dagger}$ & $58 \pm 12^{\dagger}$ & $64 \pm 9$ \\
\hline \multirow{2}{*}{$\begin{array}{l}\text { Pulmonary artery pressure } \\
(\mathrm{mmHg})\end{array}$} & SLR & $13.1 \pm 3.5$ & $15.1 \pm 4.1^{\dagger}$ & $14.9 \pm 4.8^{\dagger}$ & $14.6 \pm 4.7^{\dagger}$ & $14.3 \pm 4.3$ & $12.9 \pm 3.8$ \\
\hline & EL & $12.8 \pm 3.4$ & $15.8 \pm 4.3^{\dagger}$ & $14.2 \pm 4.0^{\dagger}$ & $14.0 \pm 3.9^{\dagger}$ & $12.4 \pm 3.9$ & $12.7 \pm 3.7$ \\
\hline \multirow{2}{*}{$\begin{array}{l}\text { Pulmonary artery wedge pressure } \\
(\mathrm{mmHg})\end{array}$} & SLR & $7.9 \pm 3.2$ & $9.7 \pm 3.8^{\dagger}$ & $9.7 \pm 4.7^{\dagger}$ & $9.5 \pm 4.2^{\dagger}$ & $7.8 \pm 3.6$ & $7.9 \pm 3.6$ \\
\hline & EL & $7.7 \pm 3.0$ & $10.4 \pm 3.5^{\dagger}$ & $9.6 \pm 3.2^{\dagger}$ & $9.0 \pm 3.4^{\dagger}$ & $7.3 \pm 3.3$ & $7.4 \pm 3.2$ \\
\hline \multirow{2}{*}{$\begin{array}{l}\text { Central venous pressure } \\
(\mathrm{mmHg})\end{array}$} & SLR & $4.5 \pm 2.4$ & $5.7 \pm 2.4^{\dagger}$ & $5.2 \pm 2.8^{\dagger}$ & $5.4 \pm 2.6^{\dagger}$ & $4.5 \pm 2.6$ & $4.9 \pm 2.4$ \\
\hline & EL & $4.6 \pm 2.4$ & $7.1 \pm 3.2^{\dagger, \neq}$ & $6.6 \pm 3.4^{\dagger, \neq}$ & $5.7 \pm 3.2^{\dagger}$ & $4.3 \pm 2.5$ & $4.5 \pm 2.6$ \\
\hline \multirow{2}{*}{$\begin{array}{l}\text { Heart rate } \\
\left(\text { beats } \cdot \min ^{-1}\right)\end{array}$} & SLR & $57 \pm 11$ & $56 \pm 10$ & $54 \pm 10$ & $57 \pm 11$ & $56 \pm 11$ & $56 \pm 11$ \\
\hline & EL & $57 \pm 11$ & $57 \pm 10$ & $56 \pm 11$ & $56 \pm 10$ & $56 \pm 10$ & $56 \pm 11$ \\
\hline \multirow{2}{*}{$\begin{array}{l}\text { LVEDAI } \\
\left(\mathrm{cm}^{2} \cdot \mathrm{m}^{-2}\right)\end{array}$} & SLR & $6.7 \pm 2.5$ & $8.0 \pm 2.9^{\S}$ & $7.5 \pm 2.9^{\S}$ & $7.3 \pm 2.8^{\S}$ & $6.6 \pm 2.8$ & $6.7 \pm 2.8$ \\
\hline & EL & $6.4 \pm 2.7$ & $7.9 \pm 2.9^{\S}$ & $7.5 \pm 2.8^{\S}$ & $7.1 \pm 2.6^{\S}$ & $6.4 \pm 2.4$ & $6.8 \pm 2.5$ \\
\hline \multirow{2}{*}{$\begin{array}{l}\text { Systemic vascular resistance } \\
\left(\text { dynes } \cdot \mathrm{sec} \cdot \mathrm{cm}^{-5}\right)\end{array}$} & SLR & $1,297 \pm 333$ & $1,336 \pm 365^{\S}$ & $1,256 \pm 293$ & $1,199 \pm 233$ & $1,174 \pm 207$ & $1,106 \pm 185$ \\
\hline & $\mathrm{EL}$ & $1,194 \pm 291$ & $1,366 \pm 337^{\S}$ & $1,296 \pm 278^{\S}$ & $1,280 \pm 265^{\S}$ & $1,164 \pm 215$ & $1,222 \pm 229$ \\
\hline
\end{tabular}

Data are expressed mean \pm SD. SLR: straight leg raising in the supine position, EL: Exaggerated lithotomy position; LVEDAI: left ventricular enddiastolic area index, Ts: baseline measurement in the supine position, T1: $1 \mathrm{~min}$ after position change, T5: 5 min after position change, T10: 10 min after position change, Ts1: 1 min after returning to the supine position, Ts5: 5 min after returning to the supine position. $* \mathrm{P}<0.05$ SLR versus EL. ${ }^{\dagger} \mathrm{P}<0.05$ versus Ts. ${ }^{\ddagger} \mathrm{P}<0.05$ between SLR and EL at each time. ${ }^{\S} \mathrm{P}<0.01$ versus Ts. 
A

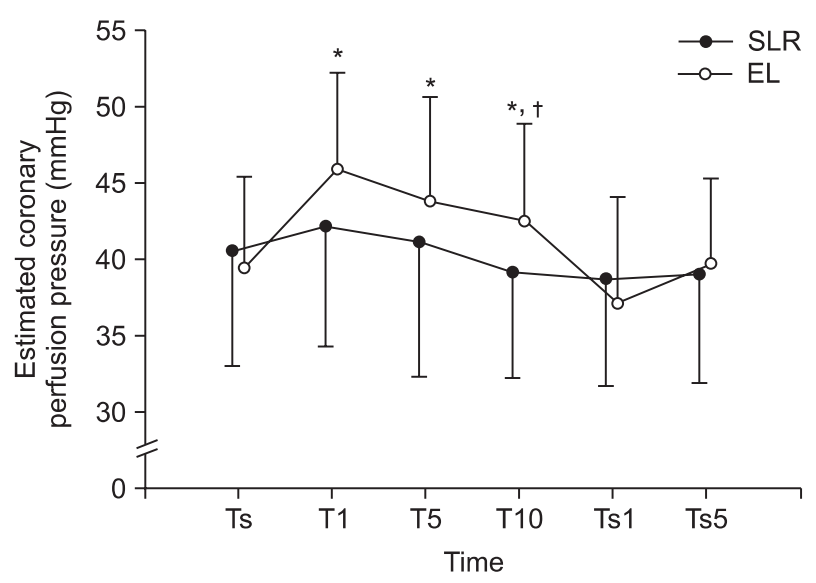

B

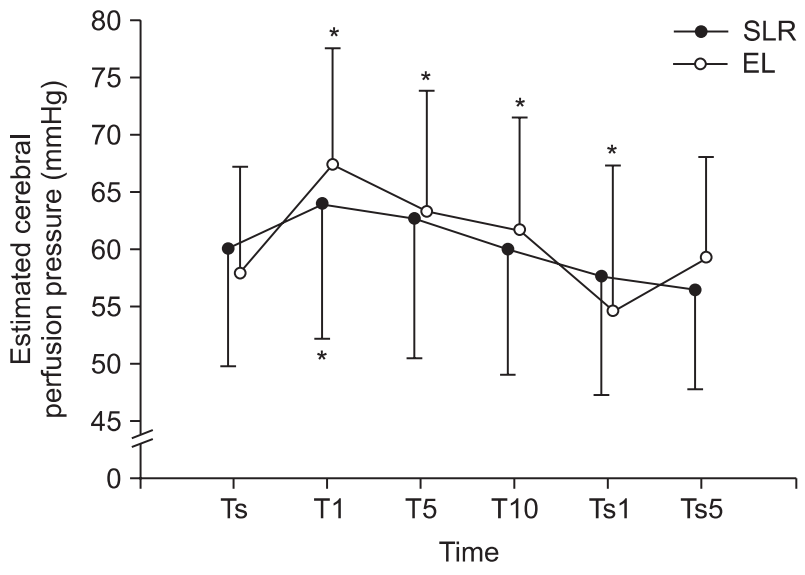

Fig. 1. Change in the estimated coronary (A) and cerebral perfusion pressure (B) during straight leg raising in the supine position (SLR) and exaggerated lithotomy position (EL). Ts: baseline measurement in the supine position, T1: 1 min after position change, T5: 5 min after position change, T10: $10 \mathrm{~min}$ after position change, Ts1: $1 \mathrm{~min}$ after returning to the supine position, Ts5: 5 min after returning to the supine position. $* \mathrm{P}<0.01$ versus Ts. ${ }^{\dagger} \mathrm{P}<0.01$ SLR versus EL at the time point.

cardiography in patients with coronary artery disease, which was similar to our study with respect to the selection of patients and measurement technique. Gaffney et al. [9], in a study of $\mathrm{CO}$ measurement with acetylene rebreathing technique in 10 healthy volunteers, explained that leg elevation may not be effective in hypovolemic patients because hypovolemiainduced vasoconstriction makes the venous blood contained in the legs reduce. Another study in anesthesized patients with coronary artery disease reported that, irrespective of the increase of stroke index, leg raising did not improve CI because heart rate decreased significantly [6]. Both leg raising and exaggerated lithotomy positions in our study did not show any significant changes in cardiac index and heart rate, which may be the effect of either beta or calcium channel blockers.

In addition, many other studies, including our study, did not show any significant change of heart rate with leg elevation $[8,9,11,12]$. In patients with right ventricular ejection fraction below $40 \%$, cardiac performance did not improve if compared to those with normal cardiac function [13]. Because volume loading in the patients with depressed right ventricular function may lead to further deterioration of myocardial function [14], it is possible that leg elevation may worsen hemodynamics in patients with heart failure. Monnet et al. [15] demonstrated that the response of CO to passive leg raising was linked to the fluid expansion response. Our study showed increased cardiac performance with passive leg raising, which means that patients under elective cardiac surgery were in preload responsiveness status.

Leg elevation increased mean BP transiently in our study. Some previous studies showed that BP increased with leg elevation $[6,12]$. Wong et al. [8] reported that raising of the legs decreased mean BP because of a decrease of diastolic pressure. On the contrary, Kyriakides and colleagues showed an increase of diastolic pressure with leg elevation [11]. Monnet et al. [15] showed that passive leg raising resulted in an increase of aortic BP in 38 out of 71 critically ill patients. Therefore, we think that there is variability in the BP responses to leg elevation among patients.

Reich and colleagues showed that mean pulmonary artery pressure and PAWP increased at $1 \mathrm{~min}$ and $3 \mathrm{~min}$ after leg raising, but not CVP and LVEDA [6]. They concluded that the increase of mean pulmonary artery pressure and PAWP may represent increased intrathoracic pressure or a decrease in left ventricular compliance. In our study, however, mean BP, mean pulmonary artery pressure, PAWP, CVP, and LVEDA increased during leg raising, which may suggest that leg raising increased preload by increased intravascular volume as well as by increased intrathoracic pressure.

Squatting position is known to increase afterload, shifting CO from systemic circulation to pulmonary circulation in patients with Tetralogy of Fallot [16]. In a normal individual, squatting increased preload, arterial BP, and CO $[17,18]$, which comes from the combined effects of enhanced venous return and increased systemic vascular resistance owing to squeezed veins and compressed arteries of the legs. In our study, full flexion of the hips and knees in the supine position increased afterload without change in $\mathrm{CO}$, increasing the estimated cerebral and coronary perfusion pressure. However, the difference of estimated cerebral perfusion pressure was negligible between two positions throughout the study period. These results suggest that the exaggerated lithotomy position may be beneficial in improving heart function, but caution should be 
taken in patients with reduced pulmonary function because this position may decrease lung compliance and increase dead space [19].

There were some limitations in our study: First, the study group consisted of coronary artery disease patients under general anesthesia that may be under fluid responsiveness condition. Therefore, the present results cannot be applied to severe hypovolemic patients who are not under the fluid responsiveness condition. However, it can be postulated that afterload could be greatly increased in the exaggerated lithotomy position than in straight leg raising. Second, we observed the effects of special positioning only during a short period of time. In clinical practice, however, $10 \mathrm{~min}$ would be a sufficient amount of time to take therapeutic actions. Third, no change of heart rate should be interpreted cautiously because most of the patients took either beta or calcium channel blockers and some patients had diabetes mellitus, which may alter the hemodynamic response to position change. Lastly, we did not directly measure but estimated cerebral and coronary perfusion pressure. Further study may be needed to address these factors.

In conclusion, this so-called exaggerated lithotomy position appeared to improve coronary perfusion pressure. Therefore, full flexion of the hips and knees in the supine position may be more useful than passive raising of the legs to immediately cope with hypotension in patients, especially those with coronary artery disease.

\section{Acknowledgements}

There is no financial support for disclosure and conflict of interest in this study.

This study was supported solely from departmental sources.

\section{References}

1. Mansour AM, Feghali JG, To'mey K, Jaroudi N. Increased intraocular pressure with head-down position. Am J Ophthalmol 1984; 98: 114-5.

2. Johnson S, Henderson SO. Myth: the Trendelenburg position improves circulation in cases of shock. CJEM 2004; 6: 48-9.

3. Mavrocordatos P, Bissonnette B, Ravussin P. Effects of neck position and head elevation on intracranial pressure in anaesthetized neurosurgical patients: preliminary results. J Neurosurg Anesthesiol 2000; $12: 10-4$.

4. Bivins HG, Knopp R, dos Santos PA. Blood volume distribution in the Trendelenburg position. Ann Emerg Med 1985; 14: 641-3.

5. Reuter DA, Felbinger TW, Schmidt C, Moerstedt K, Kilger E, Lamm $\mathrm{P}$, et al. Trendelenburg positioning after cardiac surgery: effects on intrathoracic blood volume index and cardiac performance. Eur J Anaesthesiol 2003; 20: 17-20.

6. Reich DL, Konstadt SN, Raissi S, Hubbard M, Thys DM. Trendelenburg position and passive leg raising do not significantly improve cardiopulmonary performance in the anesthetized patient with coronary artery disease. Crit Care Med 1989; 17: 313-7.

7. Coonan TJ, Hope CE. Cardio-respiratory effects of change of body position. Can Anaesth Soc J 1983; 30: 424-38.

8. Wong DH, Tremper KK, Zaccari J, Hajduczek J, Konchigeri HN, Hufstedler SM. Acute cardiovascular response to passive leg raising. Crit Care Med 1988; 16: 123-5.

9. Gaffney FA, Bastian BC, Thal ER, Atkins JM, Blomqvist CG. Passive leg raising does not produce a sustained autotransfusion effect. J Trauma 1982; 22: 190-3.

10. Mosteller RD. Simplified calculation of body-surface area. N Engl J Med 1987; 317: 1098.

11. Kyriakides ZS, Koukoulas A, Paraskevaidis IA, Chrysos D, Tsiapras D, Galiostos C, et al. Dose passive leg raising increase cardiac performance? A study using Doppler echocardiography. Int J Cardiol 1994; 44: 288-93.

12. McHugh GJ, Robinson BJ, Galletly DC. Leg elevation compared with Trendelenburg position: effects on autonomic cardiac control. Br J Anaesth 1994; 73: 836-7.

13. Bertolissi M, Da Broi U, Soldano F, Bassi F. Influence of passive leg elevation on the right ventricular function in anaesthetized coronary patients. Crit Care 2003; 7: 164-70.

14. Boldt J, Kling D, Moosdorf R, Hempelmann G. Influence of acute volume loading on right ventricular function after cardiopulmonary bypass. Crit Care Med 1989; 17: 518-22.

15. Monnet X, Rienzo M, Osman D, Anguel N, Richard C, Pinsky MR, et al. Passive leg raising predicts fluid responsiveness in the critically ill. Crit Care Med 2006; 34: 1402-7.

16. Murakami T. Squatting: the hemodynamic change is induced by enhanced aortic wave reflection. Am J Hypertens 2002; 15: 986-8.

17. O'Donnell TV, McIlroy MB. The circulatory effects of squatting. Am Heart J 1962; 64: 347-56.

18. Lewis BS, Lewis N, Gotsman MS. Effect of standing and squatting on echocardiographic left ventricular function. Eur J Cardiol 1980; 11: 405-12.

19. Choi SJ, Gwak MS, Ko JS, Lee H, Yang M, Lee SM, et al. The effects of the exaggerated lithotomy position for radical perineal prostatectomy on respiratory mechanics. Anaesthesia 2006; 61: 439-43. 